\title{
Incidence of intraglomerular platelets in steroid sensitive nephrotic syndrome
}

\author{
JMC UTTLEY, RA ELTON, CM HILL, MK MACDONALD \\ From the Department of Pathology and the Medical Computing and Statistics Unit, University of Edinburgh, \\ Edinburgh, and the Department of Pathology, The Queen's University of Belfast, Belfast
}

SUMMARY Renal biopsies from 44 patients with steroid sensitive nephrotic syndrome were examined with respect to the content of their intraglomerular platelets and compared with 18 normal control patients and with 51 patients with membranous glomerulonephritis and the nephrotic syndrome. The results suggested that platelet activity was not involved in the pathogenesis of steroid sensitive nephrotic syndrome; in the active phase of the disease the number of platelets in glomeruli is lower than that of normal controls, and this may be associated with increased sensitivity to aggregating agents as part of the nephrotic syndrome. After steroid treatment and disappearance of proteinuria, the number of intraglomerular platelets rises to normal values.

Since the features of minimal change glomerulonephritis or steroid sensitive nephrotic syndrome (SSNS) were first described in 1913,' there has been little advance in clarifying the real nature of the disease. Light microscopical examination of a renal biopsy shows little or no glomerular abnormality. The only common ultrastructural finding is fusion or effacement of epithelial foot processes, a change seen in many proteinuric states. ${ }^{23}$ Immunofluorescence microscopy is generally negative, apart from small amounts of mesangial $\mathrm{C} 3$ and IgM in some cases. ${ }^{4}$ Circulating immune complexes of IgG type have been detected in SSNS, ${ }^{5}$ but the significance of this in relation to pathogenesis is unclear. Serum complement values are usually normal, though Lewis $e t a^{6}$ found low CIq concentrations in 47 of 132 patients. IgE has been shown in the glomeruli of some patients with SSNS, ${ }^{7}$ but the role of this immunoglobulin in the disease remains controversial. Thomson $e t a l^{8}$ found that atopic features were more common in children with SSNS than in matched controls. Recent evidence suggests that SSNS may result from increased permeability of the glomerular capillary basement membrane to protein following the release of lymphokines active on the membranes. ${ }^{9-11}$

In 1970 Duffy $^{12}$ noted platelet aggregates and free fibrillar fibrin in glomeruli examined ultrastructur-

Accepted for publication 8 November 1984 ally and suggested that the coagulation process was concerned in SSNS. These results have not yet been confirmed by any controlled studies of larger series.

We have therefore examined our cases of SSNS for morphological evidence of involvement of the coagulation process and have compared them with biopsies from patients with nephrotic syndrome due to membranous glomerulonephritis (MGN) and with a group of renal biopsies which showed no glomerular abnormality on light or electron microscopy from patients assessed clinically as having no glomerular disease.

\section{Material and methods}

\section{PATIENTS}

The renal biopsies of 44 patients in whom a diagnosis of SSNS had been made by clinical and laboratory methods and by response to treatment were reviewed. In addition to light and electron microscopy, 24 of these cases had been investigated by immunofluorescence microscopy. The ages of the SSNS patients ranged from 2 to 13 years: 19 patients were aged between 2 and 5; 15 between 6 and 10; and 10 between 11 and 13. As the nephrotic syndrome itself may be associated with coagulation abnormalities, 51 cases with biopsy proven MGN were studied as controls. The ages of these patients ranged from 9 to 69 years; one patient was aged between 6 and 10; no patients were between 11 and 15 years; 3 patients were aged between 16 and 20 ; 
11 patients between 21 and 30; 5 between 31 and $40 ; 16$ between 41 and 50; 7 between 51 and 60; and 8 between 61 and 69 . In addition, 18 renal biopsies from patients without glomerular disease were examined. The biopsies in these cases had been performed because of haematuria or proteinuria, which was later found to be of non-glomerular origin; almost all dated from the early years of renal biopsy techniques, when the criteria for this examination were not clear. Of course, none of these patients suffered from or had suffered from the nephrotic syndrome. Their ages ranged from 2 to 65 years: two patients were aged between 1 and 5 years; seven between 11 and 20 years; five between 21 and 30 years; one between 41 and 50 years; one between 51 and 60 years; and two between 61 and 70 years.

In cases with more than one biopsy, only the first diagnostic biopsy was included in this investigation.

Patients treated with corticosteroids or diuretics or both within one week of, or at the time of, biopsy were identified. The prebiopsy platelet count was recorded. Renal tissue was obtained by percutaneous needle biopsy.

\section{METHODS}

\section{Light microscopy}

Specimens were fixed in corrosive formol, $4 \%$ neutral buffered formaldehyde, or alcoholic Bouin's fluid. The choice of fixative depended on which was in regular use in the laboratory at the time, and most were fixed in $4 \%$ neutral buffered formaldehyde. The processed cores were embedded in paraffin wax, sectioned at $2 \mu \mathrm{m}$, and stained by the haematoxylin and eosin, periodic acid Schiff, picro-Mallory, Martius scarlet blue, and methenamine silver methods.

\section{Electron microscopy}

Biopsy material was fixed in glutaraldehyde buffered in $0.2 \mathrm{M}$ sodium cacodylate and embedded in Araldite. Sections were cut at 50 to $60 \mathrm{~nm}$, stained with lead citrate and uranyl acetate, mounted on copper grids, and viewed on an AEI Corinth 275 or a Jeol $100 \mathrm{~S}$ electron microscope.

At least two glomeruli were examined for each biopsy. In some, more than two were available and

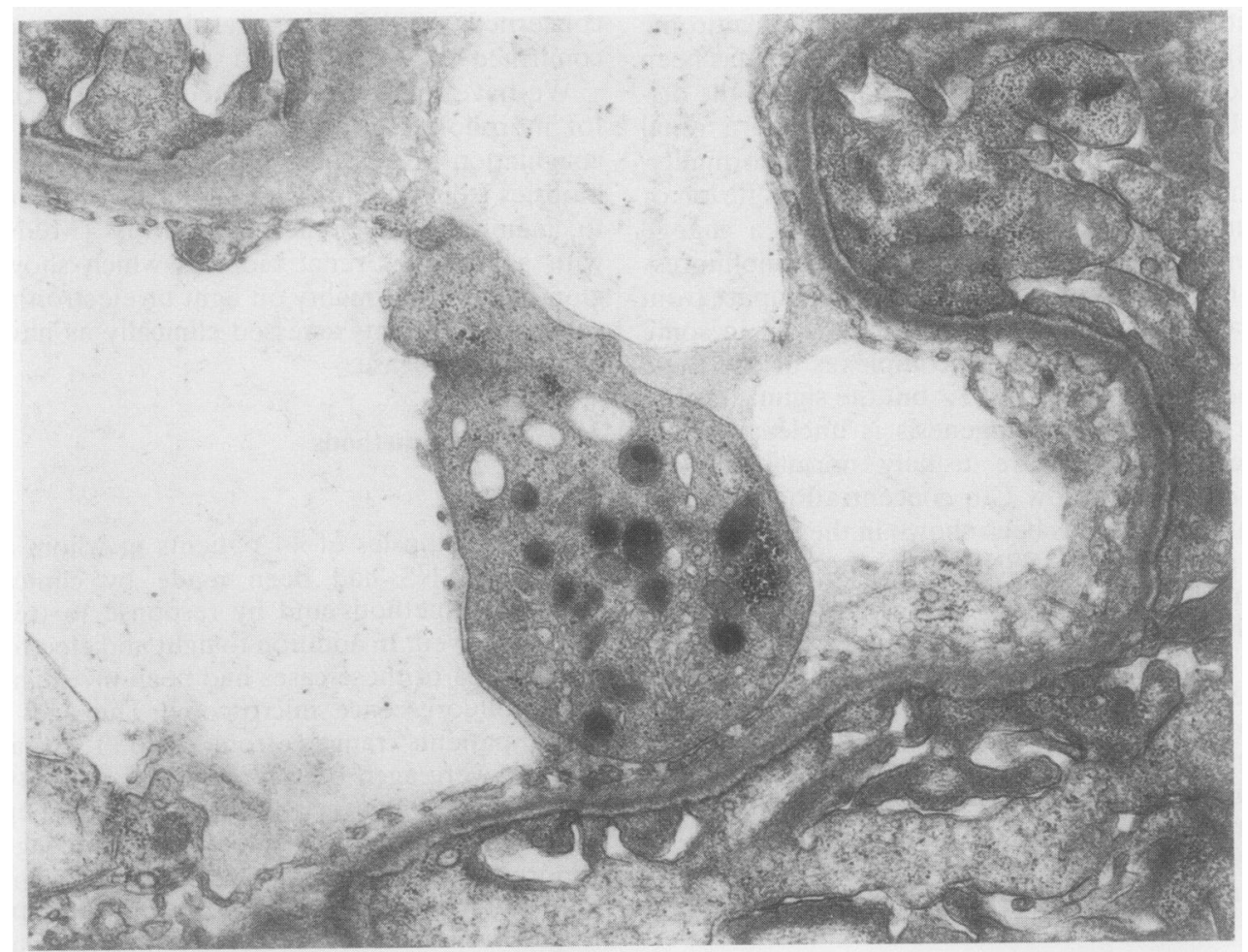

Fig. 1 Case of untreated steroid sensitive nephrotic syndrome. A single platelet lies within a glomerular capillary lumen. Pedicel structure is partially lost. $\times 15000$. 


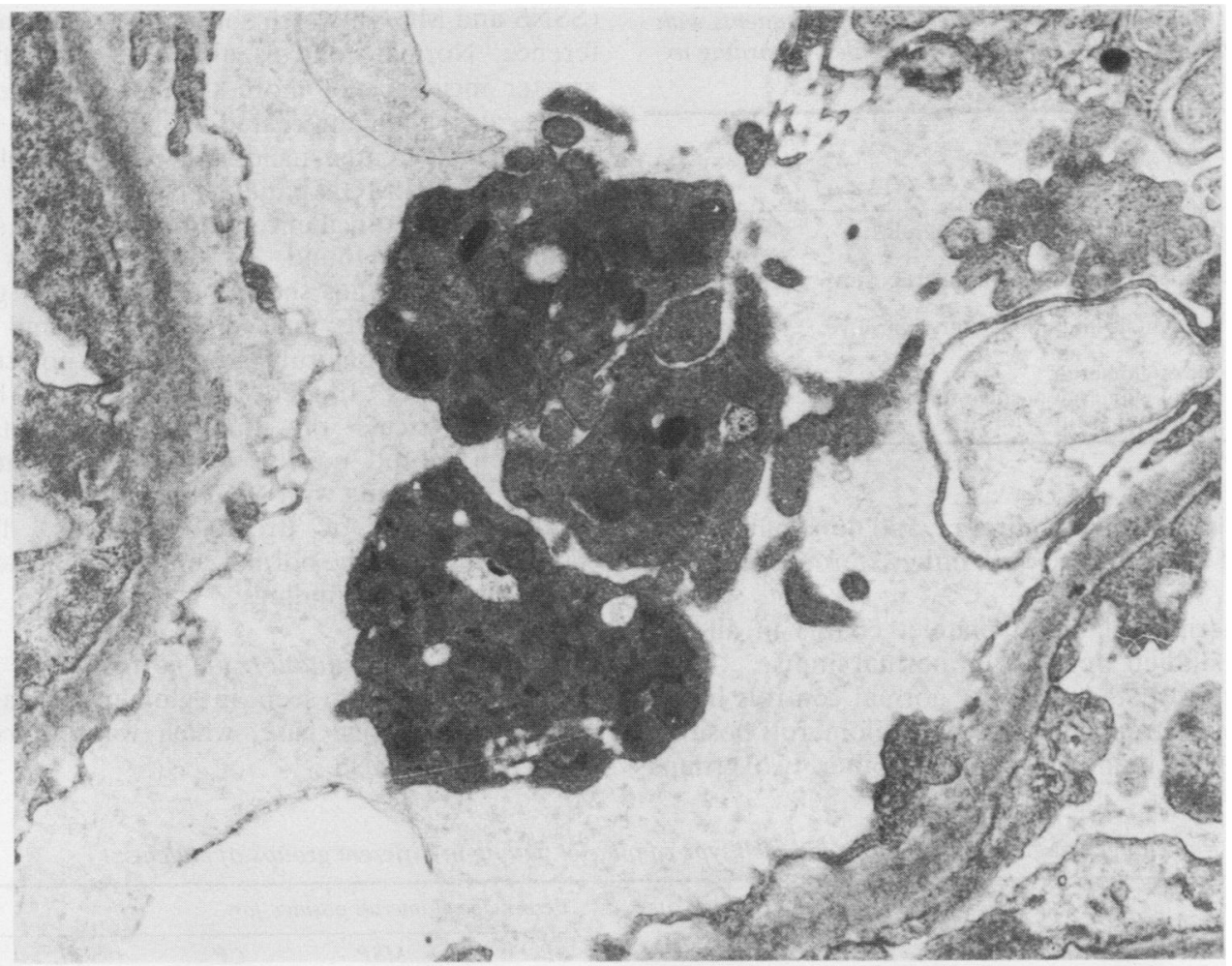

Fig. 2 Case of untreated steroid sensitive nephrotic syndrome. A clump of platelets is seen in a glomerular capillary lumen. A few small portions of endothelial cytoplasm, cut in cross section, are also seen in the lumen. Pedicel structure is partially lost. $\times 17500$.

examined, but the first two studied in each case were used for the statistical analysis to make this as simple as possible in view of the relatively small number of cases.

Intracapillary platelets were identified and allotted to three groups: $(a)$ one single platelet seen in a glomerulus (Fig. 1); (b) more than one single platelet seen in a glomerulus; (c) clumps of platelets seen in a glomerulus (Fig. 2).

The presence or absence of fibrillar fibrin in the lumen was also noted.

\section{Identification of platelets}

Platelets were not always easy to identify, and if any doubt existed as to the nature of an intracapillary structure it was deemed not to be a platelet. Likewise, material which was not identifiably fibrillar fibrin was disregarded.

\section{Statistical analysis}

Two glomeruli were examined from each patient and were scored as positive or negative for each of the three types of platelet finding. If any of these three was present the glomerulus was scored as positive for platelets. Thus for a given platelet finding each patient had 0,1 , or 2 glomeruli with that finding, and these scores were compared between groups of patients by Wilcoxon's rank sum test, corrected for ties. Comparisons of platelet incidence in the first and second glomeruli from each patient were made using McNemar's test.

\section{Results}

Table 1 shows an example of the way in which the data were analysed. From each such table the percentages of glomeruli positive for a given finding were calculated (Table 2). Table 3 shows the results of the significance tests between patient groups. In the MGN group, the history of treatment was known for only 39 of the 51 patients; since only two of these patients had received steroids there were too few observations for a useful comparison with those known not to have received steroids. No SSNS 
Table 1 Incidence of single platelets (SP) in patients with steroid sensitive nephrotic syndrome divided according to whether or not they had received steroids

\begin{tabular}{lrr}
\hline & \multicolumn{2}{l}{ Steroids } \\
\cline { 2 - 4 } & Yes & No \\
\hline $\begin{array}{l}\text { Number of patients with neither glomerulus } \\
\text { positive for SP }\end{array}$ & 9 & 22 \\
$\begin{array}{l}\text { Number of patients with one glomerulus positive } \\
\text { for SP }\end{array}$ & 7 & 4 \\
$\begin{array}{l}\text { Number of patients with both glomeruli positive } \\
\text { for SP }\end{array}$ & 1 & 1 \\
$\begin{array}{l}\text { Total number of glomeruli } \\
\text { Total number of glomeruli positive for SP }\end{array}$ & 34 & 54 \\
Percent of glomeruli positive for SP & 9 & 6 \\
\hline
\end{tabular}

patients had received diuretics, and none of the controls had been treated with either steroids or diuretics.

The peripheral blood platelet counts in all the patients studied were within normal limits.

In the untreated patients, normal controls had a significantly greater incidence of glomeruli positive for platelets than either of the other two groups
(SSNS and MGN), which showed no significant difference. Normal controls also had a significantly greater incidence of more than one platelet in a glomerulus than untreated SSNS cases, and a significantly greater incidence of single platelets than untreated MGN patients. No significant differences in platelet incidence between first and second glomeruli were found. In SSNS patients those treated with steroids showed a significantly greater incidence of more than one platelet and single platelets in a glomerulus than those not treated. MGN patients treated with diuretics had a significant excess of clumps of platelets and glomeruli scored positive for platelets compared with those patients with MGN not taking diuretics. Neither group of treated patients differed significantly from the normal controls in incidence of any of the platelet findings.

\section{Ultrastructural examination for fibrin}

Fibrillar fibrin was seen in glomerular capillary lumina in only one case, which was otherwise a classic case of SSNS.

Table 2 Percentages of glomeruli positive for each type of platelet finding in different groups of patients

\begin{tabular}{|c|c|c|c|c|c|c|}
\hline \multirow[t]{2}{*}{ Group } & \multirow[t]{2}{*}{ Subgroup } & \multirow{2}{*}{$\begin{array}{l}\text { Number of } \\
\text { patients }\end{array}$} & \multicolumn{4}{|c|}{ Percentage glomeruli positive for } \\
\hline & & & $S P$ & $M S P$ & $C P$ & $P L$ \\
\hline $\begin{array}{l}\text { Steroid sensitive nephrotic } \\
\text { syndrome }\end{array}$ & $\begin{array}{l}\text { All patients } \\
\text { Steroids } \\
\text { No steroids }\end{array}$ & $\begin{array}{l}44 \\
17 \\
27\end{array}$ & $\begin{array}{l}17 \\
26 \\
11\end{array}$ & $\begin{array}{r}5 \\
12 \\
0\end{array}$ & $\begin{array}{l}5 \\
6 \\
4\end{array}$ & $\begin{array}{l}26 \\
44 \\
15\end{array}$ \\
\hline $\begin{array}{l}\text { Nephrotic syndrome due to } \\
\text { membranous } \\
\text { glomerulonephritis }\end{array}$ & $\begin{array}{l}\text { All patients } \\
\text { Diuretics } \\
\text { No diuretics }\end{array}$ & $\begin{array}{l}51 \\
12 \\
27\end{array}$ & $\begin{array}{r}10 \\
25 \\
7\end{array}$ & $\begin{array}{l}3 \\
8 \\
2\end{array}$ & $\begin{array}{r}7 \\
21 \\
4\end{array}$ & $\begin{array}{l}19 \\
50 \\
13\end{array}$ \\
\hline Normal controls & All patients & 18 & 25 & 8 & 8 & 42 \\
\hline
\end{tabular}

$\mathrm{SP}=$ single platelets.

MSP = multiple single platelets.

$\mathrm{CP}=$ clumps of platelets.

$\mathrm{PL}=$ positive for platelets of any group.

Table 3 Results of Wilcoxon's rank sum test for group differences in platelet incidence

\begin{tabular}{|c|c|c|c|c|}
\hline & $S P$ & $M S P$ & $C P$ & $P L$ \\
\hline $\begin{array}{l}\text { SSNS patients } \\
\text { Steroid treated } y \\
\text { untreated }\end{array}$ & & & & \\
\hline MGN patients & NS & $p<0.01$ & NS & $\mathrm{p}<0.01$ \\
\hline Diuretic treated $v$ untreated & NS & NS & $p<0.01$ & $p<0.01$ \\
\hline $\begin{array}{l}\text { Untreated patients } \\
\text { SSNS } v \text { MGN } \\
\text { SSNS } v \text { normal controls } \\
\text { MGN } v \text { normal controls }\end{array}$ & $\begin{array}{l}\text { NS } \\
\text { NS } \\
\mathrm{p}<0.05\end{array}$ & $\begin{array}{l}\text { NS } \\
\text { NS }\end{array}$ & $\begin{array}{l}\text { NS } \\
\text { NS } \\
\text { NS }\end{array}$ & $\begin{array}{l}\text { NS } \\
p<0.05 \\
p<0.01\end{array}$ \\
\hline $\begin{array}{l}\text { Treated patients } \\
\text { Steroid treated SSNS } v \text { normal controls } \\
\text { Diuretic treated MGN } v \text { normal controls }\end{array}$ & $\begin{array}{l}\text { NS } \\
\text { NS }\end{array}$ & $\begin{array}{l}\text { NS } \\
\text { NS }\end{array}$ & $\begin{array}{l}\text { NS } \\
\text { NS }\end{array}$ & $\begin{array}{l}\text { NS } \\
\text { NS }\end{array}$ \\
\hline
\end{tabular}

NS = not significant.

$\mathrm{SP}=$ single platelets

MSP $=$ multiple single platelets. $\mathrm{CP}=$ clumps of platelets.

$\mathrm{PL}=$ positive for platelets of any group.

SSNS = steroid sensitive nephrotic syndrome.

MGN = nephrotic syndrome due to membranous glomerulonephritis. 


\section{Discussion}

This study has shown that in our series of 27 patients with SSNS untreated by steroids or diuretics, the incidence of platelets seen in glomerular capillaries by electron microscopy, taking all groups together, was significantly lower than the incidence in a control group of 18 patients believed to have no glomerular or haematological disease. In 17 patients with SSNS who were studied after steroid treatment there was no significant difference in the platelet incidence as compared with the control group. Similar results were noted in 27 untreated patients with MGN who also had significantly fewer platelets in glomerular capillaries than the control group; the difference was absent in the 12 patients who had received diuretic treatment before biopsy. SSNS patients are usually young, and an age difference between them and normal control patients might account for the relatively low platelet incidence. There is, however, no evidence that the platelet count rises with age; an examination of the relative ages of the SSNS and normal patients shows that half of the control patients fall within the age range of the SSNS group. It therefore seems unlikely that the age factor in the two groups was responsible for the result.

Our results suggest that the diminished platelet incidence in untreated SSNS (and MGN) may be at least partly due to the presence of the nephrotic syndrome. This syndrome is recognised as a hypercoagulable state ${ }^{13}$ and it is therefore surprising that the incidence of intraglomerular platelets in both the SSNS and the MGN groups was lower than in the control group, the difference being absent in those who had received treatment.

It is therefore of interest that some workers have shown in vitro platelet hypersensitivity to aggregating agents in nephrotic patients, correlating this with serum albumin concentrations. ${ }^{14}$ Other workers have related low antithrombin III concentrations with the thrombotic tendency in such patients. ${ }^{15}$ It may be that thrombosis in patients with the nephrotic syndrome is related to altered platelet function rather than to increased platelet numbers. This, of course, does not explain the significant decrease in platelet numbers in untreated SSNS and MGN patients when compared with controls.

Previous workers have reported varying data on the numbers of circulating platelets found in cases of SSNS. Duffy et al ${ }^{12}$ reported clumps of platelets in glomeruli in four of eight non-steroid treated SSNS patients, and this is significantly higher than our finding; clumps of platelets were present in the glomeruli of only one of our 27 cases $\left(p<0.01, \chi^{2}=\right.$ 7·3). Similarly, for patients on steroids the incidence of $5 / 12(41 \%)$ found by Duffy et al was higher than that of $2 / 17(12 \%)$ in our study, although the difference is not significant. It is not possible to compare their data for MGN patients and ours as they did not give details of diuretic treatment. Duffy et al concentrated on platelet aggregates rather than isolated or multiple single platelets. As we found these two more frequently than clumps of platelets, a meaningful direct comparison cannot be made between their study and ours.

Richman and Kasnic ${ }^{16}$ found platelets which they regarded as being in various stages of degranulation in the glomeruli of 10 of 11 cases of SSNS, aggregates being noted in four of these. Degranulating platelets were seen in 12 of 14 cases of MGN. Platelets were rarely found in their control group. No details of treatment were given, and there is no mention of the presence or absence of the nephrotic syndrome.

Our data seem to suggest that platelets are not implicated in the pathogenesis of SSNS, but that the number of platelets identifiable in glomeruli falls in the active phase of the disease, possibly because of increased sensitivity to aggregating agents as part of the nephrotic syndrome. (This factor might also explain the fall in incidence in untreated cases of MGN.) With steroid treatment, proteinuria ceases and the number of circulating platelets rises. It is, of course, possible that the rise in platelets is due simply to release from the splenic pool. It should be mentioned that antibodies with antiplatelet activity have recently been described in various conditions such as autoimmune thrombocytopenic purpura and other immunological diseases. ${ }^{17}$ It would be of interest to know whether such antibodies were present in SSNS patients. Steroid treatment might presumably modify their activity; this point requires further investigation.

We are grateful to Dr WS Uttley for access to his patients and for his cooperation in supplying us with their clinical details. We are grateful also to Dr CA Ludlam for his expert opinion on the significance of platelet concentration in children.

\section{References}

' Munk F. Klinische Diagnostik der degenerativen Nierenerkrankungen. Z Klin Med 1913;78:1-52.

${ }^{2}$ Farquhar MG, Vernier RL, Good RA. Studies on familial nephrosis. II Glomerular changes observed with the electron microscope. Am J Pathol 1957;33:791-817.

${ }^{3}$ Steiner JW, Slater RJ, Movat HZ. Studies on lipoid nephrosis in children and adolescents. I The fine structural changes in "pure" nephrosis. Lab Invest 1961;10:763-86.

4 Prasad DR, Zimmerman SW, Burkholder PM. Immunohistologic features of minimal change nephrotic syndrome. Arch Pathol Lab Med 1977;101:345-9. 
${ }^{5}$ Levinsky RJ, Malleson PN, Barratt TM, Soothill JF. Circulating immune complexes in steroid responsive nephrotic syndrome. N Engl J Med 1978;298:126-9.

- Lewis EJ, Carpenter CB, Schur PH. Serum complement component levels in human glomerulonephritis. Ann Intern Med 1971;75:555-60.

7 Gerber MA, Paronetto F. IgE in glomeruli of patients with nephrotic syndrome. Lancet 1971;i:1097-9.

${ }^{8}$ Thomson PD, Barratt TM, Stokes CR, Turner MW, Soothill JF. HLA antigens and atopic features in steroid responsive nephrotic syndrome of childhood. Lancet 1976;ii:765-8.

"Shalhoub RJ. Pathogenesis of lipoid nephrosis: a disorder of T-cell function. Lancet 1974; ii:556-60.

${ }^{10}$ Lagrue G, Xheneumont S, Branellec A, Hirbec G, Weil B. A vascular permeability factor elaborated from lymphocytes. Demonstration in patients with nephrotic syndrome. Biomedicine 1975;23:37-40.

" Boulton-Jones JM, Tulloch I, Dore B, McLay A. Changes in the glomerular capillary wall induced by lymphocyte products and serum of nephrotic patients. Clin Nephrol 1983;20:72-7.

${ }^{12}$ Duffy JL, Cinque T, Grishman E, Churg J. Intraglomerular tibrin, platelet aggregation and subendothelial deposits in lipoid nephrosis. J Clin Invest 1970;49:251-8.

${ }^{13}$ Kendall AG, Lohmann RC, Dossetor JB. Nephrotic syndrome: a hypercoagulable state. Arch Int Med 1971;127:1021-7.

${ }_{14}$ Remuzzi G, Marchesi D, Mecca G, de Gaetano G, Silver M. Platelet hypersensitivity in the nephrotic syndrome. Proc Eur Dial Transplant Assoc (Amsterdam) 1979;16:487-94.

${ }^{15}$ Kauffmann RH, Veltkamp JJ, Van Tilburg NH, Van Es LA. Acquired anti-thrombin III deficiency and thrombosis in the nephrotic syndrome. Am J Med 1978;65:607-13.

${ }^{10}$ Richman AV, Kasnic G. Endothelial and platelet reactions in the idiopathic nephrotic syndrome. An ultrastructural study. Hum Pathol 1982; 13:548-53.

${ }^{17}$ Karpatkin S. Autoimmune thrombocytopenic purpura. Blood 1980;56:329-43.

Requests for reprints to: Dr JMC Uttley, Department of Pathology, University of Edinburgh, Teviot Place, Edinburgh EH8 9AG, Scotland. 